\title{
Endoscopic Ultrasound-Guided Celiac Plexus Interventions
}

\author{
Pedro Moutinho-Ribeiro ${ }^{a, b}$ Pedro Costa-Moreira ${ }^{a, b}$ Ana Caldeira ${ }^{c}$ \\ Sílvia Leite $^{d}$ Susana Marques $^{\mathrm{e}}$ Teresa Moreira $^{\mathrm{f}}$ Nuno Nunes $^{\mathrm{g}}$ Miguel Bispo $^{\mathrm{e}}$ \\ ${ }^{a}$ Gastroenterology Department, Centro Hospitalar e Universitário São João, Porto, Portugal; ${ }^{\text {b} F a c u l t y ~ o f ~ M e d i c i n e, ~}$ \\ University of Porto, Porto, Portugal; ' CDepartment of Gastroenterology, Hospital Amato Lusitano, Castelo Branco, \\ Portugal; ${ }^{d}$ Department of Gastroenterology, Hospital da Senhora da Oliveira, Guimarães, Portugal; ${ }^{e}$ Department \\ of Gastroenterology and Digestive Endoscopy, Champalimaud Foundation, Lisbon, Portugal; ${ }^{\mathrm{f}}$ Department \\ of Gastroenterology, Centro Hospitalar Universitário do Porto, Hospital de Santo António, Porto, Portugal; \\ gDepartment of Gastroenterology, Hospital do Divino Espírito Santo de Ponta Delgada, Ponta Delgada, Portugal
}

\section{Keywords}

Celiac plexus interventions - Celiac plexus neurolysis . Celiac plexus block - Chronic pain · Pancreatic cancer . Chronic pancreatitis

\section{Abstract}

Abdominal pain related to pancreatic disease is often extremely disabling. Endoscopic ultrasound (EUS)-guided celiac plexus block (CPB) is used to control pain associated with chronic pancreatitis. EUS-guided celiac plexus neurolysis (CPN) is typically used to reduce pain associated with pancreatic cancer and can be considered early at the time of diagnosis of inoperable disease. EUS-guided celiac plexus interventions have been shown to be significantly effective in pancreatic pain relief, which is achieved in approximately $70-80 \%$ of patients with pancreatic cancer and in $50-60 \%$ of those with chronic pancreatitis. Serious complications from CPB and CPN are rare. Most frequent adverse events are diarrhoea, orthostatic hypotension, and a transient increase in abdominal pain. In this article, the Portuguese Group for UI- trasound in Gastroenterology (GRUPUGE) presents an updated perspective of the potential role of EUS-guided celiac plexus interventions, addressing the selection criteria and technical issues of different techniques and analysing recent data on their safety and efficacy.

\footnotetext{
(c) 2020 Sociedade Portuguesa de Gastrenterologia Published by S. Karger AG, Basel
}

\section{Intervenções no Plexo Celíaco Guiadas por Ecoendoscopia}

\section{Palavras Chave}

Intervenções no plexo celíaco · Neurólise do plexo celíaco · Bloqueio do plexo celíaco · Dor crónica · Cancro do pâncreas · Pancreatite crónica

Pedro Moutinho-Ribeiro and Pedro Costa-Moreira contributed equally to this study.

\section{Karger $\stackrel{2}{=}$}

This article is licensed under the Creative Commons AttributionNonCommercial-NoDerivatives 4.0 International License (CC BYNC-ND) (http://www.karger.com/Services/OpenAccessLicense) Usage and distribution for commercial purposes as well as any distribution of modified material requires written permission.
Pedro Moutinho-Ribeiro Gastroenterology Department Centro Hospitalar e Universitário São João Al. Prof. Hernani Monteiro, PT-4200-319 Porto (Portugal) pmoutinhoribeiro@gmail.com 


\section{Resumo}

A dor abdominal relacionada com doença pancreática pode ser extremamente incapacitante. O bloqueio do plexo celíaco (CPB) guiado por ecoendoscopia (EUS) é utilizado para controlo da dor associada à pancreatite crónica. A neurólise do plexo celíaco (CPN) guiada por EUS é utilizada na terapêutica da dor associada ao cancro do pâncreas, podendo ser utilizada numa fase precoce, após o diagnóstico de doença irressecável. As intervenções no plexo celíaco guiadas por EUS demonstraram ser eficazes no alívio da dor. O sucesso terapêutico é alcançado em aproximadamente 70 a $80 \%$ dos pacientes com cancro do pâncreas, e em 50 a $60 \%$ dos pacientes com pancreatite crónica. São raras as complicações severas associadas a CPB e CPN. Os eventos adversos mais frequentemente documentados correspondem a diarreia, hipotensão ortostática e a aumento transitório da dor abdominal. Neste artigo, o GRUPUGE apresenta uma perspetiva das intervenções no plexo celíaco guiadas por EUS, onde se abordam os critérios de seleção, questões técnicas relativas aos procedimentos e se analisam os dados sobre sua segurança e eficácia. ๑ 2020 Sociedade Portuguesa de Gastrenterologia Published by S. Karger AG, Basel

\section{Introduction}

Pancreatic cancer and chronic pancreatitis are commonly associated with intense and often refractory pain [1]. Pain usually occurs in the occult stage of the disease and gradually worsens as the disease progresses [2]. Moreover, cancer pain markedly reduces the quality of life and is considered a prognostic factor for survival.

Therefore, palliative pain control is crucial in the context of advanced pancreatic cancer [3, 4]. Non-narcotic medical therapies are often inadequate, and opioids commonly induce nausea, constipation, and other side effects [5]. If patients have refractory pain or cannot tolerate increasing amounts of opioid medications, endoscopic ultrasound (EUS)-guided celiac plexus block (CPB) and neurolysis (CPN) may play an important role [4]. CPB is a temporary treatment and most commonly refers to the injection of a steroid and a long-acting local anaesthetic into the celiac plexus. In contrast, CPN generally refers to injection of alcohol or phenol, agents that induce ablation of the nerve fibres, conducting to a more permanent effect [6].

The anatomical location of celiac plexus, near the origin of the celiac trunk and superior mesenteric artery, is easily accessed by EUS. This approach, providing a near-field and

EUS-Guided Celiac Plexus Interventions real-time visualization, is preferable to the percutaneous one, and is considered nowadays, the safer, faster, and easier technique for celiac plexus interventions [7].

In this chapter, the Portuguese Group for Ultrasound in Gastroenterology (GRUPUGE) presents a perspective of the potential role of EUS-guided celiac plexus interventions, addressing the selection criteria and technical issues of different techniques and analysing emerging data on their efficacy and safety. A systematic literature search was performed until January 2020 using PubMed, Medline, Scopus, and Google, using the keywords "chronic pancreatitis," "pancreatic cancer," "pancreatic pain," "endoscopic ultrasound," "celiac plexus block," "celiac plexus neurolysis," and "celiac ganglia." Prospective/comparative studies and international consensus statements/ management guidelines were preferred. The final manuscript was revised and approved by all members of the Governing Board of the GRUPUGE.

\section{Indications and Contraindications}

$\mathrm{CPB}$ is indicated for management of pain associated with chronic pancreatitis. CPN is mostly indicated in patients with pancreatic cancer [4]. A recent consensus statement recommends against EUS-CPN for the treatment of chronic pancreatitis pain [8]. Given how rarely EUS-CPN is used in chronic pancreatitis and the relatively high proportion of reported significant complications, EUS-CPN for chronic pancreatitis pain may (for unknown reasons) be riskier than EUS-CPN for malignancy.

CPN should be considered when pancreatic cancer patients have intolerable adverse effects to opioid therapy such as drowsiness, somnolence, confusion, delirium, dry mouth, anorexia, constipation, nausea, and vomiting, or if an analgesic ceiling is achieved because of neurotoxicity [9].

The timing of the celiac intervention relative to pain onset appears to be an important predictor of pain response in patients with pancreatic cancer. Early pancreatic cancer pain appears to derive mainly from the celiac plexus involvement, while pain during the terminal stages of the disease may also involve other visceral and somatic nerves [10]. Thus, CPN performed soon after the onset of pain from pancreatic cancer may increase the rate of response.

However, the potential benefit of early EUS-CPN in the quality of life of these patients is still undefined. Current guidelines for the management of pancreatic 

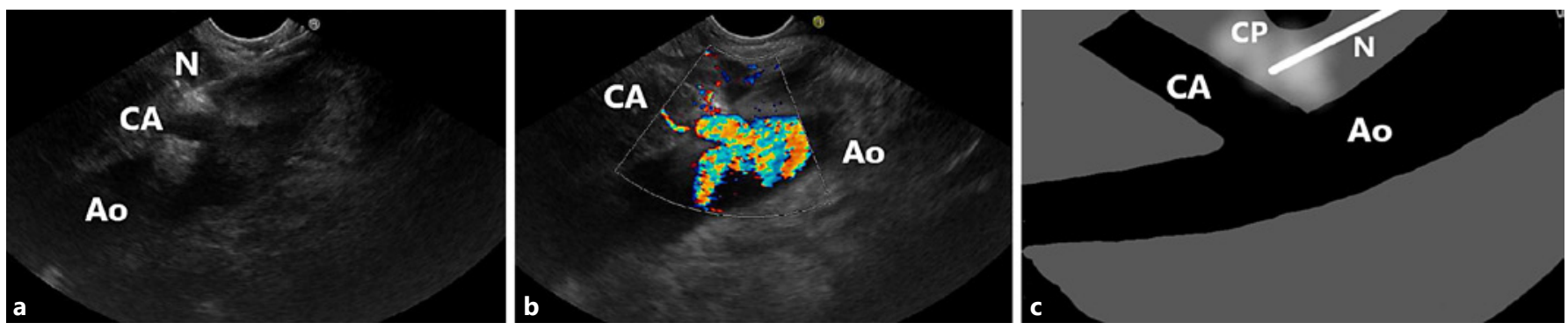

Fig. 1. Relevant anatomy for the $\mathrm{CPN}$ and $\mathrm{CPB}$ procedure. EUS image (a) with colour Doppler (b), and diagrammatic scheme (c) from the lesser curvature of the stomach, showing the celiac plexus located anterior to the aorta. Note the needle at the base of the celiac artery. Ao, aorta; CA, celiac artery; CP, celiac plexus; N, needle.

cancer do not state specific recommendations regarding the timing for EUS-CPN in the treatment of cancer-associated pain [11]. The ESMO guidelines state that EUS-CPN should be carried out in the presence of resistant pain and only if the clinical condition of the patient is not poor [12]. A single randomized, doubleblind, controlled trial pointed out to a potential benefit of early EUS-CPN, performed at the time of the diagnosis of unresectable pancreatic cancer, in patients with abdominal pain at presentation [13]. According to a recent consensus statement, when on-site cytopathology is available, patients with painful inoperable pancreas cancer should undergo EUS-CPN at the time of diagnosis [8]. Despite this, in current clinical practice, EUS$\mathrm{CPN}$ is commonly considered late after the diagnosis of pancreatic cancer, being conventionally reserved for refractory pain after failure of a step-wise analgesic ladder strategy or when side effects of such therapy become difficult to control.

Potential contraindications are thought to include impaired coagulation (international normalized ratio [INR] $>1.5$ and/or platelets $<50,000 / \mathrm{mm}^{3}$ ), inadequate visualization or access to the region of the celiac artery (CA) take-off [14], modified anatomy from prior surgery, congenital abnormalities, or bowel obstruction.

\section{Anatomy}

Although the terms "celiac plexus" and "splanchnic nerves" are often used interchangeably, they are anatomically distinct structures $[15,16]$. The splanchnic nerves are located above and posterior to the diaphragm and anterior most often to the 12th thoracic vertebra. The celiac plexus is located below and anterior to the diaphragm and surrounds the origin of the celiac trunk. Celiac plexus is a network of ganglia that relays preganglionic sympathetic and parasympathetic efferent fibres and visceral sensory afferent fibres to the upper abdominal viscera. The celiac plexus transmits the sensation of pain from the pancreas. The visceral sensory afferent fibres transmit nociceptive impulses from the liver, gallbladder, pancreas, spleen, adrenal glands, kidneys, distal oesophagus, and bowel to the level of the distal transverse colon. Located in the retroperitoneum just inferior to the celiac trunk and along the bilateral anterolateral aspects of the aorta, between the levels of the T12-L1 disc space and L2, the celiac plexus can easily be reached by EUS [6].

\section{Procedural Description}

\section{Pretreatment Procedure}

The procedure usually is performed under sedation on an outpatient basis. Due to its invasiveness, a platelet count and coagulation profile should be assessed before the procedure [17]. In addition, antiplatelet and anticoagulation therapies must be reviewed, and appropriate modification or cessation of these agents is advised given the risk of bleeding [18]. Patients are initially hydrated with 500-1,000 mL normal saline to minimize the risk of hypotension usually associated with CPN. Throughout the procedure, patients are continuously monitored by an automated non-invasive blood pressure device and pulse oximeter [14].

Taking into account the infectious adverse events related to $\mathrm{CPB}$, usually related to the use of a steroid agent, some authors suggested that prophylactic antibiotics should be considered, especially in patients under acid
Moutinho-Ribeiro et al. 
suppression therapy [19]. For the choice of antibiotic regimen, local guidelines should be followed.

\section{General Endoscopic Technique}

The technique for EUS-guided CPN and CPB is identical, the main difference being the injected substances. A 22- or 19-gauge EUS fine-needle aspiration needle is usually used. If a specially designed 20 -gauge "spray needle" with multiple side holes is available, it could be used to spread the desired agent through a larger area [20].

The endosonographic anatomic landmark of the celiac ganglia is typically located at the posterior gastric wall, just below the gastroesophageal junction, approximately $40 \mathrm{~cm}$ from the incisors. By EUS, the ganglia may be seen as two small $(2-3 \mathrm{~mm})$ elongated hypoechoic structures with hyperechoic central foci, anterolateral to the aorta, adjacent to the celiac trunk, just distal to the take-off of the CA from the aorta (Fig. 1) [21-23]. For a better individualization of vascular structures, a Doppler study is usually performed.

The needle tip is placed slightly anterior and cephalad to the origin of the CA or directly into the ganglia if these can be identified as distinct structures. A syringe containing the injectate is attached to the needle, and aspiration is performed to rule out inadvertent blood vessel penetration prior to any injection.

\section{Celiac Plexus Neurolysis}

EUS-guided techniques for performing celiac neurolysis may be categorized as those which involve diffuse injection into the celiac plexus (CPN) and those in which the celiac ganglia are directly targeted (celiac ganglia neurolysis, CGN).

Two approaches are currently used when performing EUS-CPN [4]. The classic approach, known as the central technique, involves injection of the agent at the base of the CA. In the second approach, the bilateral technique, the neurolytic agent is injected on both sides of the CA. There are limited and conflicting data regarding the efficacy of single versus bilateral injection [24]. Generally, a mixture of $30 \%$ by volume of $0.25 \%$ bupivacaine with $70 \%$ by volume of $98 \%$ dehydrated alcohol is used. Data to guide the optimal injectate type, volume, and mixing ratio are still lacking. The total volume of solution injected is usually 10-20 $\mathrm{mL}$ and before withdrawing the needle, a small amount of normal saline solution $(3 \mathrm{~mL})$ should be flushed to fully clear the whole medication [25], and to avoid a possible caustic effect of the alcohol on the gastric mucosa.

EUS-Guided Celiac Plexus Interventions

\section{Celiac Plexus Block}

The technique for CBP is essentially the same as for CPN. Generally, in a unilateral approach, $20 \mathrm{~mL}$ of $0.25 \%$ bupivacaine followed by $40-80 \mathrm{mg}$ of triamcinolone are injected. If a bilateral approach is chosen, the dose is divided in two and injected in both sides of the celiac plexus [6].

\section{Alternative Modalities}

Celiac Ganglia Neurolysis

Research has focused on the ability of EUS injection therapy to target the celiac ganglia specifically (CGN). A recent multicentre randomized trial [26] showed a superiority of direct CGN over $\mathrm{CPN}$ in pain response rate on the 7 th day after the procedure. Although these studies demonstrate significantly better short-term pain relief with the direct ganglia injection approach, data referring to the long-term efficacy is still lacking, and the procedural technique is yet to be standardized. Although some authors did not show significant differences in pain relief between CGN and bilateral or broad plexus EUS-CPN [8], according to a Brazilian consensus statement, in patients with clearly visible ganglia, CGN appears to have better efficacy and should be preferable to CPN [27].

\section{Broad Plexus Neurolysis}

An alternative approach that has been described for patients with advanced abdominal cancer involves EUSguided broad plexus neurolysis (BPN), in which the injection is performed at the level of the superior mesenteric artery (generally with a 25-gauge needle), resulting in a broader distribution of neurolysis. In one trial with 67 patients assigned to either conventional $\mathrm{CPN}$ or BPN, patients in the BPN group had a significantly better shortand long-term pain relief [28].

\section{Radiofrequency Ablation}

Recently, radiofrequency ablation (RFA) has been used for ablation of celiac ganglia in patients with pancreatic cancer $[29,30]$. According to the recent literature, RFA has been developed mainly for the treatment of locally advanced pancreatic cancer. For this reason, it is not considered an alternative in current clinical practice in the treatment of pancreatic pain.

A recently published study [30] has found that EUSRFA provided better pain relief without any difference in the rate of adverse events. Importantly, $21 \%$ of patients with persistent pain after CPN could be successfully managed with RFA. The proposed advantages of EUS-RFA over EUS-CPN using alcohol include a more predictable 
area of necrosis and immediate symptom relief. However, the data are limited and the ideal settings of RFA have yet to be determined.

\section{Postprocedural Follow-Up}

After the procedure, the patient's vital signs should be monitored (temperature, blood pressure, and heart rate) for at least $2 \mathrm{~h}$. Prior to discharge, blood pressure should be checked both in supine and erect positions to assess postural hypotension [6].

\section{Adverse Events}

Adverse events related to EUS-guided CPN and CPB occur in up to $30 \%$ of cases, most commonly diarrhoea (7\%), increase in abdominal pain (2-4\%), and hypotension (4\%). All symptoms are usually mild and selflimiting [31-33]. Serious adverse events related to EUSguided CPN $(0.2 \%)$ and $\mathrm{CPB}(0.6 \%)$ were reported and include bleeding, retroperitoneal abscess, abdominal ischemia, permanent paralysis (including diaphragmatic paralysis), pneumothorax, peritonitis, infections, liver or spleen infarction, and death $[33,34]$. Possible mechanisms of injury include diffusion of neurolytic agent adjacent to the $\mathrm{CA}$, resulting in arterial vasospasm reflecting the sclerosing effect of absolute ethanol and arterial embolization following injection [25].

Due to some serious adverse events that have been reported with EUS-guided CPN, it should not be used for the treatment of chronic pancreatitis pain.

Infectious complications of EUS-CPB are uncommon. In a series of 90 patients, only 1 developed an infectious complication (a peripancreatic abscess), which resolved with a 2-week course of antibiotics [35]. The authors speculated that there may have been a predisposition to infection because the patient was taking a proton pump inhibitor at the time of the procedure and may have had gastroduodenal colonization with bacteria. The bactericidal nature of ethanol (used in CPN) appears to minimize this risk for infection.

\section{Efficacy}

Studies have shown that there is variability in the efficacy regarding pain relief associated with $\mathrm{CPB}$ and $\mathrm{CPN}$. Although $\mathrm{CPB}$ and $\mathrm{CPN}$ are considered safe procedures, the long-term efficacy of $\mathrm{CPB}$ and $\mathrm{CPN}$ has been limited in terms of duration of pain relief, and the effects on qual- ity of life are controversial [6]. A meta-analysis of EUSguided CPB and CPN reported response rates of $59 \%$ in chronic pancreatitis and $80 \%$ in pancreatic cancer; however, most of these patients continued to take analgesic medications [36].

The average length of relief obtained with CPB is approximately 3 months, and this procedure should, therefore, be considered a temporizing measure [37].

The early use of CPN in patients with inoperable cancer may improve pain relief compared with conventional pain management. In a randomized control trial, $96 \mathrm{pa}-$ tients were randomly assigned to early EUS-CPN or conventional pain management, if EUS and EUS-guided fine-needle aspiration cytology confirmed inoperable adenocarcinoma [13]. Pain scores, morphine equivalent consumption, and quality of life scores were assessed at 1 and 3 months. At 3 months, patients treated with CPN had significantly greater pain relief, with a trend toward lower morphine consumption, so the authors concluded that EUS-CPN can be considered in such patients at the time of diagnostic and staging EUS. Nevertheless, no difference between the groups was seen in quality of life scores or survival.

\section{Key Points}

- Pain is common and frequently disabling in patients with pancreatic cancer and chronic pancreatitis.

- EUS-guided celiac plexus interventions, in combination with conventional analgesia, may be useful for pain management in patients with pancreatic disease (malignant or chronic pancreatitis).

- EUS-CPB is a transient interruption of the plexus by local anaesthetic, while EUS-CPN leads to a prolonged interruption of the transmission of pain from the celiac plexus by the use of chemical agents such as alcohol or phenol.

- Significant pain control is achieved with EUS-CPN in the setting of pancreatic cancer $(80 \%)$. More modest results are seen in patients with abdominal pain secondary to chronic pancreatitis after EUS-CPB (59\%). Effects on quality of life are controversial.

- The safety profile of EUS-guided CPN and CPB is favourable. Procedure-related complications include transient pain exacerbation, transient hypotension, or transient diarrhoea. Although most complications are not serious, major adverse events (nearly $0.2 \%$ ), such as retroperitoneal bleeding, abscess, and ischemic complications, occasionally occur. Due to some serious adverse events that have been reported with EUS-guided CPN, it should not be use for the treatment of chronic pancreatitis pain.

- CPN should not be considered when surgery may still be an option for patient treatment.

- BPN and RFA are promising alternative techniques, but further studies are needed for its validation in clinical use.
Moutinho-Ribeiro et al. 


\section{Disclosure Statement}

All authors have no personal conflicts of interest or financial relationships relevant to this publication to disclose.

\section{Author Contributions}

Pedro Costa-Moreira and Pedro Moutinho-Ribeiro contributed equally to this paper: article concept and design, literature review, and draft of the manuscript. All other authors critically revised it and approved the final version.

Funding Sources

No funding was received.

\section{References}

1 Ventafridda GV, Caraceni AT, Sbanotto AM, Barletta L, De Conno F. Pain treatment in cancer of the pancreas. Eur J Surg Oncol. 1990 Feb;16(1):1-6.

2 Yan BM, Myers RP. Neurolytic celiac plexus block for pain control in unresectable pancreatic cancer. Am J Gastroenterol. 2007 Feb; 102(2):430-8.

3 Smyth EN, Shen W, Bowman L, Peterson P, John W, Melemed A, et al. Patient-reported pain and other quality of life domains as prognostic factors for survival in a phase III clinical trial of patients with advanced breast cancer. Health Qual Life Outcomes. 2016 Mar; 14(1):52-52.

4 Moutinho-Ribeiro P, Liberal R, Macedo G. Endoscopic ultrasound in pancreatic cancer treatment: facts and hopes. Clin Res Hepatol Gastroenterol. 2019 Oct;43(5): 513-21.

5 Schmidt-Hansen M, Bennett MI, Arnold S, Bromham N, Hilgart JS. Oxycodone for cancer-related pain. Cochrane Database Syst Rev. 2017 Aug;8(8):CD003870-70.

6 Sachdev AH, Gress FG. Celiac Plexus Block and Neurolysis: A Review. Gastrointest Endosc Clin N Am. 2018 Oct;28(4):579-86.

7 Fusaroli P, Jenssen C, Hocke M, Burmester E, Buscarini E, Havre RF, et al. EFSUMB Guidelines on Interventional Ultrasound (INVUS), Part V - EUS-Guided Therapeutic Interventions (Short Version). Ultraschall Med. 2016; 37(4):412-20.

8 Wyse JM, Battat R, Sun S, Saftoiu A, Siddiqui AA, Leong AT, et al. Practice guidelines for endoscopic ultrasound-guided celiac plexus neurolysis. Endosc Ultrasound. 2017 NovDec;6(6):369-75.

9 Kaufman M, Singh G, Das S, Concha-Parra R, Erber J, Micames C, et al. Efficacy of endoscopic ultrasound-guided celiac plexus block and celiac plexus neurolysis for managing abdominal pain associated with chronic pancreatitis and pancreatic cancer. J Clin Gastroenterol. 2010 Feb;44(2):12734.

10 Cornman-Homonoff J, Holzwanger DJ, Lee KS, Madoff DC, Li D. Celiac Plexus Block and Neurolysis in the Management of Chronic Upper Abdominal Pain. Semin Intervent Radiol. 2017 Dec;34(4):376-86.
11 Tempero MA, Malafa MP, Chiorean EG, Czito B, Scaife C, Narang AK, et al. Pancreatic Adenocarcinoma, Version 1.2019. Natl Compr Canc Netw. 2019 Mar;17(3): 202-10.

12 Ducreux M, Cuhna AS, Caramella C, Hollebecque A, Burtin P, Goéré $\mathrm{D}$, et al.; ESMO Guidelines Committee. Cancer of the pancreas: ESMO Clinical Practice Guidelines for diagnosis, treatment and follow-up. Ann Oncol. 2015 Sep;26 Suppl 5:v56-68.

13 Wyse JM, Carone M, Paquin SC, Usatii M, Sahai AV. Randomized, double-blind, controlled trial of early endoscopic ultrasoundguided celiac plexus neurolysis to prevent pain progression in patients with newly diagnosed, painful, inoperable pancreatic cancer. J Clin Oncol. 2011 Sep;29(26): 3541-6.

14 Levy MJ, Chari ST, Wiersema MJ. Endoscopic ultrasound-guided celiac neurolysis. Gastrointest Endosc Clin N Am. 2012 Apr;22(2): 231-47.

15 Brown DL, Moore DC. The use of neurolytic celiac plexus block for pancreatic cancer: anatomy and technique. J Pain Symptom Manage. 1988;3(4):206-9.

16 Ischia S, Ischia A, Polati E, Finco G. Three posterior percutaneous celiac plexus block techniques. A prospective, randomized study in 61 patients with pancreatic cancer pain. Anesthesiology. 1992 Apr;76(4):534-40.

17 Pasha SF, Acosta R, Chandrasekhara V, Chathadi KV, Eloubeidi MA, Fanelli R, et al.; ASGE Standards of Practice Committee. Routine laboratory testing before endoscopic procedures. Gastrointest Endosc. 2014 Jul;80(1): 28-33.

18 Veitch AM, Vanbiervliet G, Gershlick AH, Boustiere C, Baglin TP, Smith LA, et al. Endoscopy in patients on antiplatelet or anticoagulant therapy, including direct oral anticoagulants: British Society of Gastroenterology (BSG) and European Society of Gastrointestinal Endoscopy (ESGE) guidelines. Endoscopy. 2016 Apr;48(4):c1.

19 Chantarojanasiri T, Aswakul P, Prachayakul V. Uncommon complications of therapeutic endoscopic ultrasonography: What, why, and how to prevent. World J Gastrointest Endosc. 2015 Aug;7(10):960-8.
20 Adler DG, Conway JD, Coffie JM, Disario JA, Mishkin DS, Shah RJ, et al.; ASGE TECHNOLOGY COMMITTEE. EUS accessories. Gastrointest Endosc. 2007 Dec;66(6):107681.

21 Snady H. Interventional endoscopy, neoadjuvant therapy and the gastroenterologist. Hematol Oncol Clin North Am. 2002 Feb;16(1): 53-79.

22 Collins D, Penman I, Mishra G, Draganov P. EUS-guided celiac block and neurolysis. Endoscopy. 2006 Sep;38(9):935-9.

23 Michaels AJ, Draganov PV. Endoscopic ultrasonography guided celiac plexus neurolysis and celiac plexus block in the management of pain due to pancreatic cancer and chronic pancreatitis. World J Gastroenterol. 2007 Jul; 13(26):3575-80.

24 Sahai AV, Lemelin V, Lam E, Paquin SC. Central vs. bilateral endoscopic ultrasoundguided celiac plexus block or neurolysis: a comparative study of short-term effectiveness. Am J Gastroenterol. 2009 Feb;104(2): 326-9.

25 Minaga K, Takenaka M, Kamata K, Yoshikawa T, Nakai A, Omoto S, et al. Alleviating Pancreatic Cancer-Associated Pain Using Endoscopic Ultrasound-Guided Neurolysis. Cancers (Basel). 2018 Feb;10 (2):50.

26 Doi S, Yasuda I, Kawakami H, Hayashi T, Hisai H, Irisawa A, et al. Endoscopic ultrasound-guided celiac ganglia neurolysis vs. celiac plexus neurolysis: a randomized multicenter trial. Endoscopy. 2013;45(5): 362-9.

27 Maluf-Filho F, de Oliveira JF, Mendonça EQ, Carbonari A, Maciente BA, Salomão BC, et al. II Brazilian consensus statement on endoscopic ultrasonography. Endosc Ultrasound. 2017 Nov-Dec;6(6):359-68.

28 Sakamoto H, Kitano M, Kamata K, Komaki $\mathrm{T}$, Imai $\mathrm{H}$, Chikugo $\mathrm{T}$, et al. EUS-guided broad plexus neurolysis over the superior mesenteric artery using a 25 -gauge needle. Am J Gastroenterol. 2010 Dec;105(12):2599606.

29 Jin ZD, Wang L, Li Z. Endoscopic ultrasoundguided celiac ganglion radiofrequency ablation for pain control in pancreatic carcinoma. Dig Endosc. 2015 Jan;27(1):163-4. 
30 Bang JY, Sutton B, Hawes RH, Varadarajulu S. EUS-guided celiac ganglion radiofrequency ablation versus celiac plexus neurolysis for palliation of pain in pancreatic cancer: a randomized controlled trial (with videos). Gastrointest Endosc. 2019 Jan;89(1): 58-66.e3.

31 McGreevy K, Hurley RW, Erdek MA, Aner MM, Li S, Cohen SP. The effectiveness of repeat celiac plexus neurolysis for pancreatic cancer: a pilot study. Pain Pract. 2013 Feb; 13(2):89-95.

32 Nagels W, Pease N, Bekkering G, Cools F, Dobbels P. Celiac plexus neurolysis for abdominal cancer pain: a systematic review. Pain Med. 2013 Aug;14(8):1140-63.
33 Luz LP, Al-Haddad MA, DeWitt JA. EUSguided celiac plexus interventions in pancreatic cancer pain: an update and controversies for the endosonographer. Endosc Ultrasound. 2014 Oct;3(4):213-20.

34 Jang HY, Cha SW, Lee BH, Jung HE, Choo JW, Cho YJ, et al. Hepatic and splenic infarction and bowel ischemia following endoscopic ultrasound-guided celiac plexus neurolysis. Clin Endosc. 2013 May;46(3):306-9.

35 Gress F, Schmitt C, Sherman S, Ciaccia D, Ikenberry S, Lehman G. Endoscopic ultrasoundguided celiac plexus block for managing abdominal pain associated with chronic pancreatitis: a prospective single center experience. Am J Gastroenterol. 2001 Feb;96(2):409-16.
36 Puli SR, Reddy JB, Bechtold ML, Antillon MR, Brugge WR. EUS-guided celiac plexus neurolysis for pain due to chronic pancreatitis or pancreatic cancer pain: a meta-analysis and systematic review. Dig Dis Sci. 2009 Nov; 54(11):2330-7.

37 LeBlanc JK, DeWitt J, Johnson C, Okumu W, McGreevy K, Symms M, et al. A prospective randomized trial of 1 versus 2 injections during EUS-guided celiac plexus block for chronic pancreatitis pain. Gastrointest Endosc. 2009 Apr;69(4):835-42. 